Abstract

\title{
Improving Crop Adaptation through Improved Phenology Prediction: A Case Study with Chickpea ${ }^{\dagger}$
}

\author{
Yash Chauhan ${ }^{1, *}$ and Merrill Ryan ${ }^{2}$ \\ 1 Department of Agriculture and Fisheries, Queensland Government, Kingaroy, QLD 4610, Australia \\ 2 Department of Agriculture and Fisheries, Hermitage Research Facility, Hermitage, QLD 4370, Australia; \\ merrill.ryan@daf.qld.gov.au \\ * Correspondence: yash.chauhan@daf.qld.gov.au \\ + Presented at the Third International Tropical Agriculture Conference (TROPAG 2019), Brisbane, Australia, \\ 11-13 November 2019.
}

Published: 6 March 2020

\begin{abstract}
Flowering time is a key phenological stage which in chickpea has been considered to be mainly driven by photoperiod and temperature. However, in spite of being able to be measured very accurately, these two factors are not able to fully account for seasonable and locational variation in flowering time. Analysis of published information and flowering data collected in various projects on chickpea has led to the discovery of soil water being an additional critical driver of flowering and pod set in chickpea. High soil water status delays flowering in chickpea. An equation that captures the effect of soil water on flowering time has been developed. This equation enables prediction of flowering time in a very diverse range of environments and seasons with a high accuracy, further suggesting a putative role of soil water in modulating flowering. Similar improvements in prediction of flowering time have been noted in lentil and wheat also suggesting that soil water, similar to temperature and photoperiod, may have a universal role in modulating flowering of winter crops. The delaying effect of high soil water, while on one hand could assist in avoiding frosts, on the other hand it could lead to greater soil water and heat stress later in the season if the delay is considerable. This new research will enable more effective optimisation of flowering time of winter crops in different environments and provide breeders and physiologists the opportunity to unravel the genetic and physiological basis of phenological responses to soil water and exploit this response to improve crop adaptation to climatically variable environments.
\end{abstract}

Keywords: Cicer arietinum; flowering; photoperiod; soil water; temperature

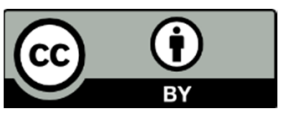

(C) 2020 by the authors. Licensee MDPI, Basel, Switzerland. This article is an open access article distributed under the terms and conditions of the Creative Commons Attribution (CC BY) license (http://creativecommons.org/licenses/by/4.0/). 